\title{
Energy-Efficient Economy as a Condition of Human Capital Reproduction
}

\author{
O.V. Pogharnitskaya ${ }^{1, *}$, E.G. Matyugina ${ }^{2}$ and E.S. Terdi ${ }^{3}$ \\ "Corresponding author: pov@tpu.ru
}

\author{
${ }^{1}$ National Research Tomsk Polytechnic University, Tomsk State University of Control Systems and Radioelectronics, Tomsk, Russia \\ ${ }^{2}$ National Research Tomsk State University, Tomsk State University of Control Systems and Radioelectronics, Tomsk, Russia \\ ${ }^{2}$ Western Siberian Branch of the Russian State University of Justice, Tomsk, Russia
}

\begin{abstract}
The article is devoted to assessment of quantitative and qualitative human capital reproduction in energy-efficient economy provided by research of correlation between dynamics of energy consumption and transformation of life quality. The purpose of the research is to assess the role of energy-efficient economy in shaping of the conditions for human capital reproduction as a way of investment into its qualitative development. To achieve this purpose transformation of traditional spheres of sustainable development together with the implementation of the energy-efficient economy approaches in terms of maintaining of quality of human capital are considered. We conduct a study comparing several dependencies: development of productive powers - increasing requirements for the quality of human capital; ensuring effective reproduction - improving the quality of life, improving the quality of life associated with the economic system; GDP - energy consumption; GDP - $\mathrm{CO}_{2}$ emissions. The object of the study is dynamics of indicators characterizing the above dependencies, a number of the countries members of the OECD - having an expanded human capital reproduction. Examined countries demonstrate correlation between energy efficiency of economy and quality of human capital with rather a wide variability of chosen indicators. Results of the research may become a base for forecast of development of studied indicators and their factors.
\end{abstract}

Keywords: life quality, energy consumption, human capital, $\mathrm{CO}_{2}$ emissions, environment.

\section{Introduction}

Growth of the productive forces determines the transformation of the requirements for the labor resources; it calls for improvement of their ability to solve more complicated production problems and provokes deterioration of the characteristics of the labor resources. At the same time life quality is as a result of the economic management and reflects the conditions of life activity, affecting the efficiency of human capital reproduction. Economic system plays a dual role: negative one - in terms of deteriorative impact and positive one - in terms of both compensation of the latter and evolution of the characteristics of human capital.

Limited natural resources adjusts the approaches to organization of their extraction, cardinally changes the content of these approaches and the system of the principles and criteria of the assessment of the life activity conditions. In particular, limited energy resources together with increasing of their consumption (according to the British Petroleum's forecast, under invariable conditions energy consumption will increase by $34 \%$ until 2035; demand will mainly increase due to the countries with actively developing economics, while in the OECD's countries there will be a low growth [1]) and intensification of anthropogenic impact on the environment results in the preconditions for considering of energy-efficient economy as a significant (but not the only one!) tool for maintenance of human capital reproduction.

Dynamics of energy consumption by the households is one of the characteristics of the conditions for human capital reproduction. On the one hand, it shows the households' welfare (their provision with personal transport, home appliances, etc.); on the other hand - demonstrates the level of negative impact on the environment, leading to deterioration of health and ability to work. In particular, in 2000 the percent of Global Burden in DALYs, induced by air pollution and other reasons connected with the energy sector, is as follows: household Solid Fuel - 2,6\% (currently state - «stable»), energy systems occupational - 0,5\% (currently state - «uncertain»), outdoor air pollution - $0,8 \%$ (currently state - «stable»), climate change $-0,4 \%$ (currently state - «rising») [2].

A number of researchers have established a direct correlation between quality of life that determinates the conditions for human capital reproduction, and energy consumption [3-7]. At the same time, in such a research there is necessity to reveal connection with specificity of consumers' behavior in timing and geographical contexts in order to make proper assessment of influence of the different factors (such as culture, welfare, priorities and so on) on the dynamics of the ecological problems [8-10]. The concept of assessing energy consumption as the main driving force of social development was included in the Cotterrell's sociological theory and later on was developed by a number of researchers [11,12]. There is a tendency of a primary emphasis of researchers' attention on the deterioration of environmental quality («ecological trace») [13]. In particular, some researchers consider population size and welfare as the main determinants of the national anthropogenic impact on the environment [14]. 


\section{Problem Statement}

Within the framework of the present research the relationship between the dynamics of energy consumption and transformation of life quality is considered, assuming the absence of direct correlation of these parameters as a hypothesis, which is connected with the orientation of the economic systems to energy efficiency.

\section{Research Questions}

The production creates a number of dependencies that play an important role in the choice of development strategy:

- The intensification of production forces development presupposes an increase of the requirements for the quality of human capital - to its efficient reproduction;

- Ensuring efficient human capital reproduction presupposes the growth of life quality, whose material basis is laid by economic system;

- Focus of the economic system on the use of traditional energy resources implies the formation of direct relationship between GDP's dynamics and power-intensity;

- The threat of exhaustion of traditional energy resources stimulates searching for alternative energy resources,;

- The deteriorative impact of production onto human capital takes place both directly during production process and indirectly through pollution of environment;

- The change of economic power considered in the context of GDP's dynamics, correlates with the indicator of $\mathrm{CO}_{2}$ emissions.

Two groups of the indicators are chosen to characterize direct impact on the consumers, on their consumption, welfare, and life conditions. The indicators that reflect the role of a man in energy consumption compose the first group of the indicators: economic aspect - level of GDP per capita and productivity (GDP per hour worked) [15]; energy aspect-Energy supply per unit of GDP, Energy supply per capita, Primary energy supply and intensity of use [16]; environmental aspect - change in CO2 emission intensities per GDP [16]. The indicators that characterize life quality and directly correlate with the energy and environmental aspects of human capital reproduction compose the second group of the indicators (all data were received from web-site Human development reports UNDP): Life Expectancy Index; Expected years of schooling; Infant mortality rate. As research object of proposed dependencies the groups of OECD's countries were selected: countries with the birthrate above the level of regular reproduction (Israel, Turkey); countries with the high rates of natural growth combined with significant level of migration growth (Sweden, Norway, Canada).

\section{Purpose of the Study}

The purpose of the research is to assess the role of energy-efficient economy in shaping the conditions for human capital reproduction as a way of investment into its qualitative development.

\section{Research Methods}

In the framework of the presented research, a systematic method was used, based on the study of the relationship between the components of the human capital reproduction, evaluation of the factual material and generalization of the results. It required the use of tools for analysis, synthesis, observation and comparison.

\section{Findings}

First of all, the conditions for human capital reproduction should be analyzed taking the level of GDP per capita and productivity (GDP per hour worked) as a resulting indicator (figure 1). 


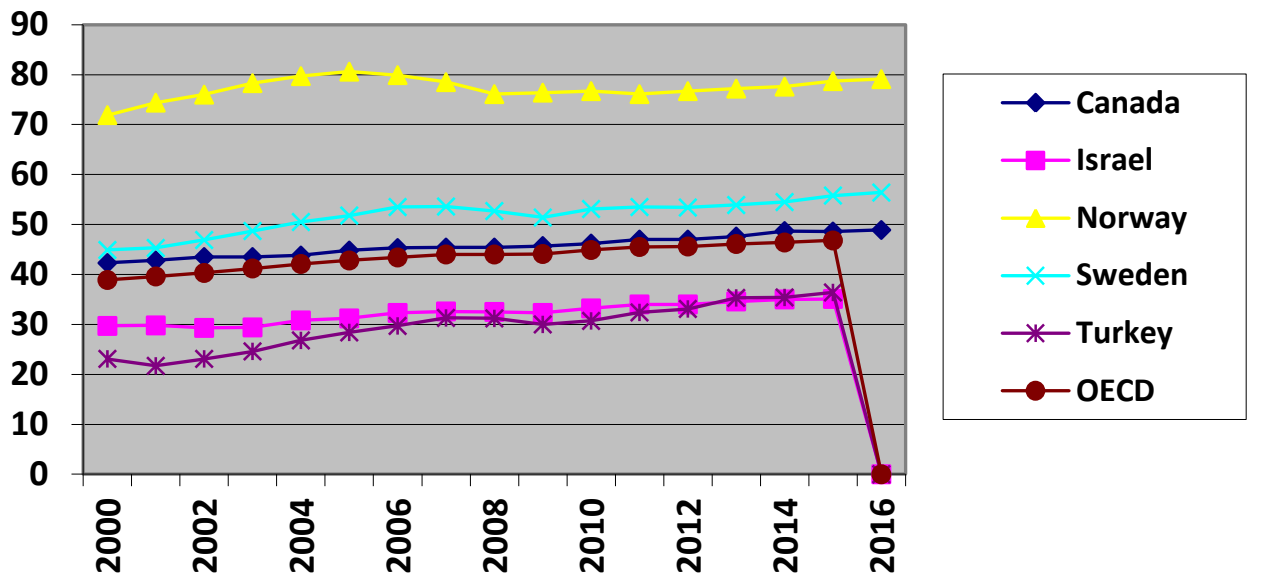

Figure 01. Level of GDP per capita and productivity (GDP per hour worked), USD, constant prices, 2010 PPPs Source: compiled by the authors based on data analytical statement $[15,17]$

How does the power-intensity change in this case? All studied countries show decline of power production per a unit. As for energy consumption per capita there is a difference: while in the most countries this indicator declines, in Israel, Turkey and Norway it grows up
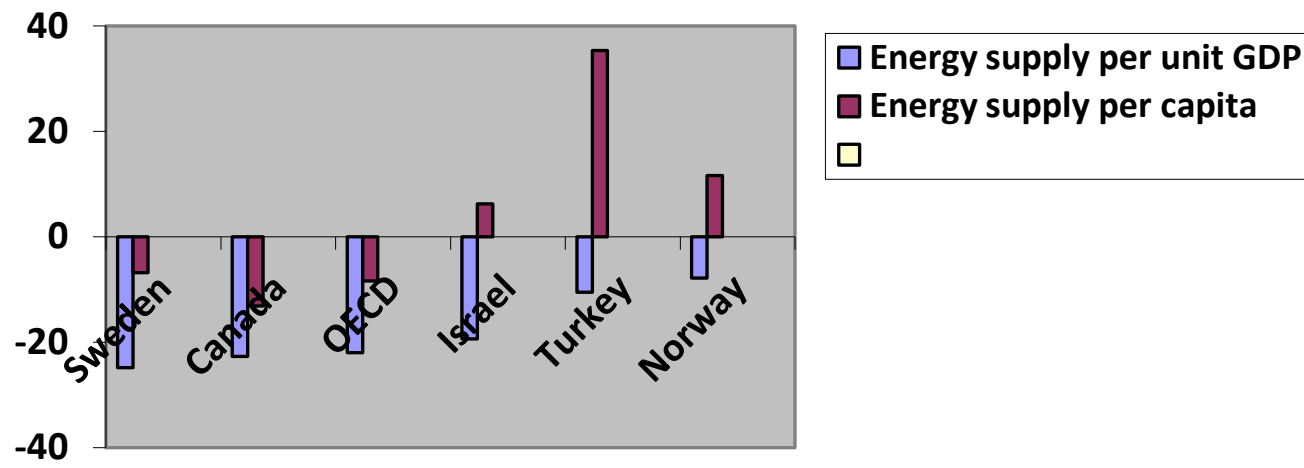

Figure 2. Change in energy intensity 2000-2014

Source: compiled by the authors based on data analytical statement [17]

One of the factors of declining of the GDP's power-intensity is alternative energy sources. Indeed, Sweden with the largest declining indicator is a leader in terms of share of renewable energy resources in total energy production. In Turkey and Israel this share is much less.

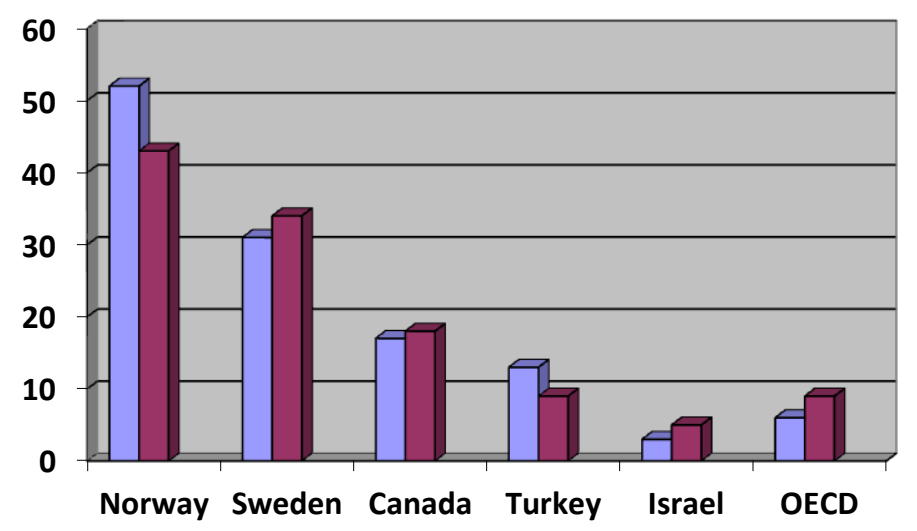

Figure 03. Share of renewables in total primary energy supply and in electricity production (Renewable energy supply, \% TEPS) Source: compiled by the authors based on data analytical statement $[15,17]$

In the structure of energy consumption of each studied country there is such a component as alternative power production. The latter helps to reduce $\mathrm{CO}_{2}$ emissions and, therefore, improve the conditions of human capital reproduction. In the energy consumption structure the biggest share of solid fossil fuels' consumption belongs to Turkey 
$(30,4 \%)$. Share of oil varies from $24,3 \%$ (Sweden) to $41,2 \%$ (Israel). Nuclear energy is obviously preferable in Sweden $(35,1 \%)$. Canada also uses nuclear energy but three times less $(10,7 \%)$ than oil $(30,4 \%)$ and gas $(33,3 \%)[16]$.

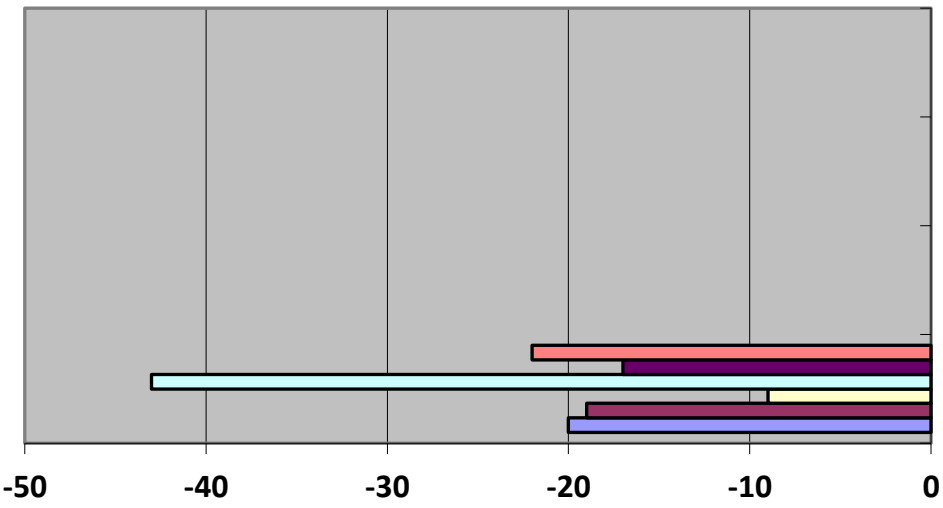

\begin{tabular}{|l|}
\hline$\square$ OECD \\
$\square$ Turkey \\
$\square$ Sweden \\
$\square$ Norway \\
$\square$ Israel \\
$\square$ Canada \\
\hline
\end{tabular}

Figure 04. Change in $\mathrm{CO}_{2}$ emission intensities per GDP 2000-2014

Source: compiled by the authors based on data analytical statement $[15,17]$

All said above allows suggesting the growth of human capital quality. What does statistic say? All studied countries show an increase of the estimated indicators (Figure 05).
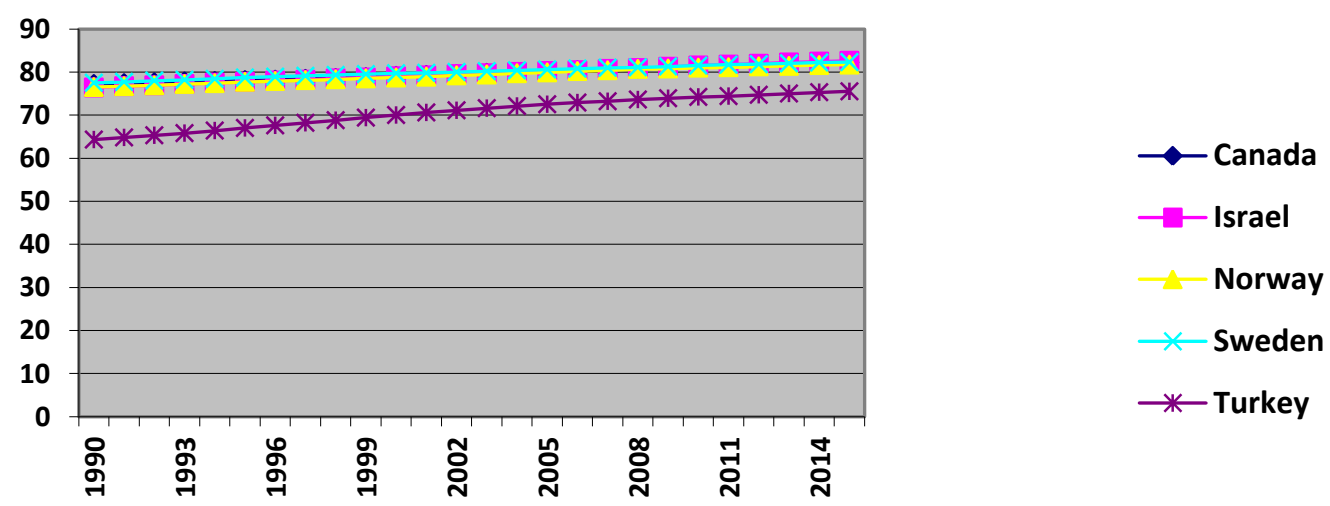

Figure 05. Life Expectancy Index,

Source: compiled by the authors based on data analytical statement [15, 17]

Together with positive tendencies, the difference in the dynamics of mentioned indicators should be noted. In particular, Turkey is characterized by the largest positive dynamics. A number of highly industrialized countries, including examined countries, showed the tendency a bit earlier. The intensity of indicators' dynamics is reflected in following colors: decrease of an indicator - black colour; moderate increase of an indicator - white colour; intensive increase of an indicator - grey colour.

The indicators are used in the diagrams: ecology - change in $\mathrm{CO}_{2}$ emission intensities per GDP; economy - level of GDP per capita and productivity (GDP per hour worked); power generation - energy supply per unit of GDP, energy supply per capita, primary energy supply and intensity of use; the quality of life - this complex indicator is explained in separate diagram on the right from main diagram by 3 indicators: Life Expectancy Index, Expected Years of Schooling and Infant Mortality Rate. 


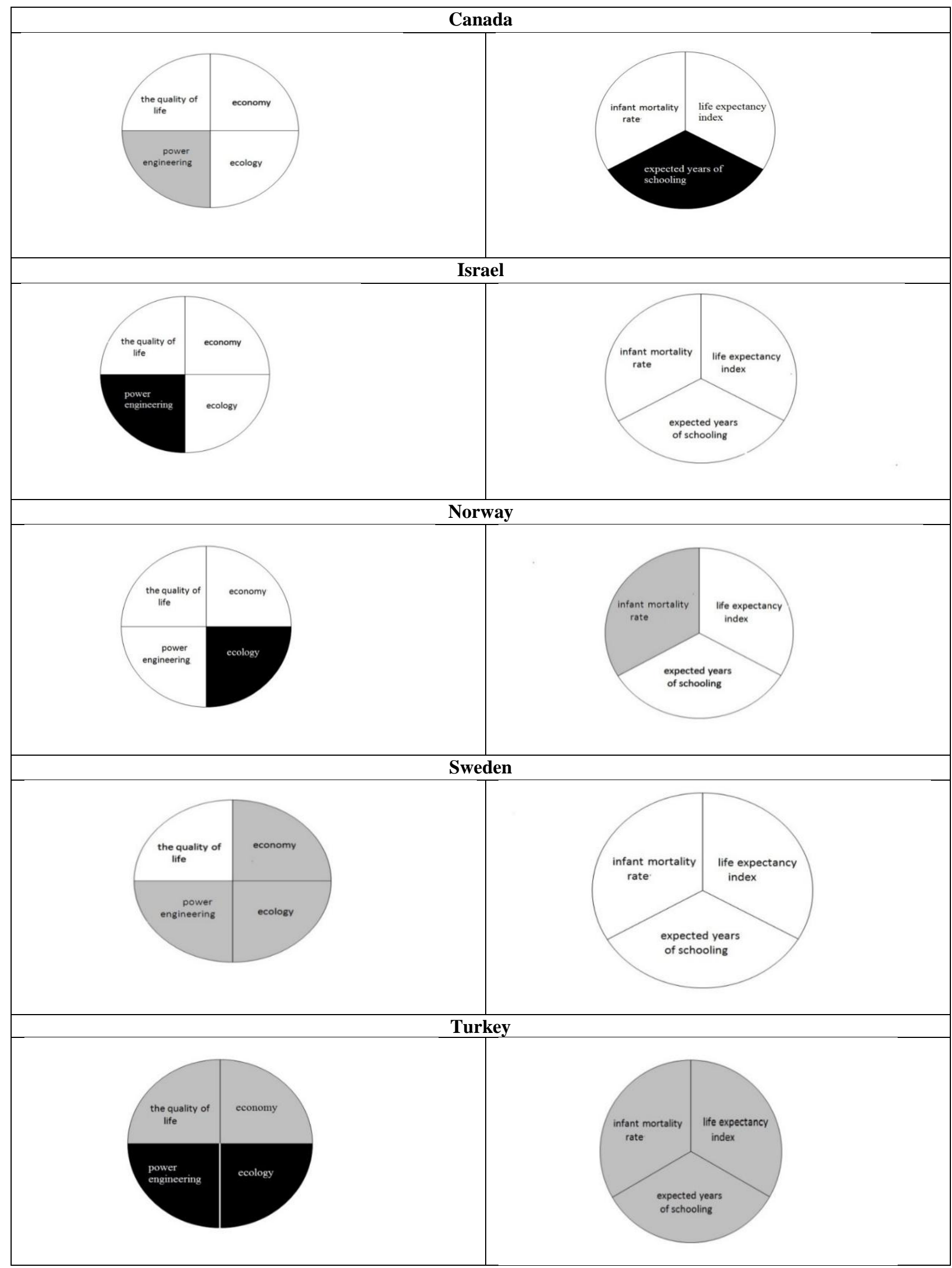

Figure 08. Dynamics of selected indicators by country

Source: compiled by the authors. 


\section{Conclusion}

Conducted research allows stating the fact that development of an energy-efficient economy is with the growth of the quality of human capital. The results of the research demonstrate the focus of the countries on development of an energy-efficient economy providing the conditions for expanded human capital reproduction. The countries chosen for the research and characterized by growth of population, have shown the following tendencies:

- In all countries, there is the growth of life quality; and the highest growth of all indicators is registered in Turkey, significant reduction of infant mortality - in Norway;

- All countries show the growth in the level of GDP per capita and productivity;

- Some dissonance in dynamic of reduction of $\mathrm{CO}_{2}$ emissions was noted: the most significant indicators were registered in Sweden (leader in the share of alternative energy);

- Same situation there is in respect of such indicators as energy supply per unit of GDP, energy supply per capita, primary energy supply and intensity of use.

\section{References}

1. BP energy outlook. Retrieved form: https://www.bp.com/en/global/corporate/energy-economics/energyoutlook.html. Accessed: 12.08.2018 (2016).

2. GEA, 2012: Global Energy Assessment - Toward a Sustainable Future, Cambridge University Press, Cambridge, UK and New York, NY, USA and the International Institute for Applied Systems Analysis, Laxenburg, Austria. Retrieved from: http://www.iiasa.ac.at/web/home/research/Flagship-Projects/Global-Energy-Assessment/HomeGEA.en.html/. Accessed: 12.05.2017 (2012).

3. E. Azar, C. Nikolopoulou, S.Papadopoulos, Integrating and optimizing metrics of sustainable building performance using human-focused agent-based modelling. Applied Energy, 183(C), 926-937. DOI: 10.1016/j.apenergy.2016.09.022 (2016).

4. J.G. Lambert, C.A.S. Hall, S. Balogh, A. Gupta, M. Arnold, Energy, EROI and quality of life. Energy Policy, 64, 153-167. DOI: 10.1016/j.enpol.2013.07.001 (2014).

5. C.C. Lee, Energy consumption and GDP in developing countries: A cointegrated panel analysis. Energy Economics 27(3), 415-427 (2005).

6. L. Liu, T. Chen, Y. Yin, Energy consumption and quality of life: Energy efficiency index. Energy Procedia, 88, 224-229 (2016).

7. C. Pasten, J.C. Santamarina, Energy and quality of life. Energy Policy, 49, 468-476. DOI: 10.1016/j.enpol.2012.06.051 (2012).

8. S. Bin, H. Dowlatabadi, Consumer lifestyle approach to US energy use and the related CO2 emissions. Energy Policy, 33(2), 197-208 (2005).

9. C. Fang, S. Wang, G. Li, Changing urban forms and carbon dioxide emissions in China: A case study of 30 provincial cities. Applied Energy, 158(C), 519-531 (2015).

10. Y. Yamagata, H.Y. Seya, Simulating a future smart city: An integrated land use-energy model. Applied Energy, 112, 1466-1474. DOI: 10.1016/j.apenergy.2013.01.061 (2013).

11. J.D. Hamilton, What is an oil shock? Journal of Econometrics, 113(2), 363-398. DOI: 10.1016/S03044076(02)00207-5 (2003).

12. L.J. Schipper, S. Meyers, Energy efficiency and human activity: Past trends and future prospects. Cambridge: Cambridge University Press (1992).

13. E.G. Matyugina, O.V. Pogharnitskaya, N.V. Dmitrieva, L.S. Grinkevich, Z.O. Selenchuk, A.B. Strelnikova, Evaluating perspectives of economy «decarbonation». In A.Yu. Dmitriev (Ed.), IOP Conference Series: Earth and Environmental Science, 43. Tomsk. Russia. IOP. DOI:10.1088/1755-1315/43/1/012042 (2016). [in Rus.].

14. R. York, E.A. Rosa, T. Dietz, Footprints on the Earth: The environmental consequences of modernity. American Sociological Review, 68(2), 279-300 (2003).

15. IEA, World energy balances. IEA World Energy Statistics and Balances (database documentation). Retrieved from: http://www.iea.org/statistics/relateddatabases/ worldenergystatisticsandbalances/. Accessed: 12.04.2017 (2014).

16. OECD. Energy intensity and mix, in Environment at a Glance. (OECD Indicators, OECD Publishing, Paris). Retrieved from: http://www.oecd.org/env/environment-at-a-glance-19964064.htm/. Accessed 12.04.2017 (2016).

17. IEA World energy balances. IEA World Energy Statistics and Balances (database). Retrieved from: http://www.iea.org/statistics/ relateddatabases/worldenergystatisticsand balances/ Accessed 21.04.2018 (2016). 